\title{
O Vocabulário do Escritor João Brasil
}

\author{
El Vocabulario del Escritor João Brasil
}

The Vocabulary of the author João Brasil

\author{
Eliane Pereira Machado Soares ${ }^{1}$ \\ Renan Torres da Costa ${ }^{2}$
}

\begin{abstract}
Resumo
Esta produção apresenta uma pesquisa sobre o vocabulário da obra literária do autor memorialista João Brasil Monteiro, da cidade de Marabá, Estado do Pará. O autor, cujas obras são objeto dessa pesquisa, publicou 11 obras não ficcionais, de caráter memorialista que, em sua maioria, retratam a história da referida cidade, desde seus primórdios, abrangendo os mais diversos aspectos de sua existência. O referencial teórico e metodológico remete à análise léxico-semântica de lexias, organizadas em campos lexicais por Coseriu (1981) e aos estudos da Lexicologia, Lexicografia e Terminologia. A composição do corpus se faz com três de suas obras com o qual se elaborará um vocabulário. A organização deste vocabulário é feita por meio de ficha catalográfica, de forma semasiológica, os verbetes são apresentados em ordem alfabética, com as respectivas informações gramaticais, definições e remissivas, para tanto, os dados lexicais serão manipulados por meio do programa computacional Lexique Pro, que permite construir dicionários eletrônicos. Até o momento já foram identificados mais de 300 vocábulos e fraseologismos, representativos do vocabulário do autor e do falar regional.
\end{abstract}

Palavras-Chave: Léxico; Vocabulário; Falar e Literatura Regional.

\section{Resumen}

Esta producción presenta una investigación acerca del vocabulario de la obra literaria del autor memorialista João Brasil Monteiro, de la ciudad de Marabá, Estado de Pará. El autor, cuyas obras son objeto de esta investigación, publicó 11 obras no ficticias, de carácter memorialista que, en su mayoría, retratan la historia de dicha ciudad desde su principio, abarcando los más diversos aspectos de su existencia. El referencial teórico y metodológico remite al análisis léxico-semántica de lexías, organizadas en campos lexicales por Coseriu (1981) y a los estudios de la Lexicología, Lexicografía y Terminología. La composición del corpus se hace con tres de sus obras con las que se elaborará un vocabulario. La organización de este vocabulario se realiza por medio de una ficha de catalogación, de forma semasiológica, las entradas se presentan en orden alfabético, con las respectivas informaciones gramaticales, definiciones y remisivas, para tanto, los datos lexicales serán manipulados a través del programa computacional Lexique Pro, que permite construir los diccionarios electrónicos. Hasta el momento ya se han identificado más de 300 vocablos y fraseologismos, representativos del vocabulario del autor y del discurso regional.

Palabras claves: Léxico; Vocabulario; Discurso y Literatura Regional.

\begin{abstract}
Tais producion presents one research about the vocabulary of the literary work, the author memorable João Brasil Monteiro, from the city of Marabá, state of Pará. The author whose literary are the subject of this research, published 11 (eleven) literary works not fictions, memorable charater the majority of those retreated the history

\footnotetext{
${ }^{1}$ Doutora em Linguística pela Universidade Federal do Ceará; Professor Associado I da Universidade Federal do Sul e Sudeste Pará (2013), do Instituto de Letras, Linguística e Artes/faculdade de Estudos da Linguagem Campus Universitário de Marabá; Marabá, Pará, Brasil; eliane @ unifesspa.edu.br.

${ }^{2}$ Graduando em Letras/Português pela Universidade Federal do Pará; Marabá, Pará, Brasil; torres.renan181@gmail.com.
} 
of Marabá city, since its beginnings, covering the most diverse aspects of its existence. The theoretical and methodological reference refers to the lexical semantic analysis of fields by Coseriu (1981) and theoretical studies of Lexicology, Lexicography and Terminology. The composition of the corpus is done with three of his works whit which to elaborate a vocabulary. The organization of this vocabulary is done by means of a catalytic record, in a sematological form, the entries are presents in alphabetical order, with the respective grammatical information, definitions and references, so the lexical date will be manulated through the Lexique Pro computer program, wich allows your to build eletronic dictionares. Until today more than 300 words and phraseologisms have been identified representing the author's and regional vocabulary speech.

Keywords: Lexicon; Vocabulary; Speaking and Regional Literature.

\section{Introdução}

Dentre todos os níveis da língua, admite-se que o léxico é o que mais permite o conhecimento da realidade de um grupo social em qualquer época. A razão disso é que a interação humana da depende da nomeação das coisas do universo onde cada grupo social se insere e que é determinante para sobrevivência do indivíduo, como parte de uma sociedade, e da própria sociedade. Esse nomear é historicamente determinado pelas convenções e necessidades sociais de cada grupo em cada época, conforme as inovações tecnológicas, a natureza circundante e o surgimento de ideias, valores e crenças, e por esta razão, como enfatizam teóricos como Abbade (2009; 2012), Coseriu (1981), Isquerdo (2012) e Nunes (2014), dentre outros. Sendo assim, estudar o vocabulário de um indivíduo é uma forma de se conhecer a língua em uma época, tanto no aspecto social quanto no linguístico, nesse sentido, uma obra literária pode ser uma boa fonte de pesquisa do léxico, pois traz as escolhas lexicais de uma individuo, a partir de seu conhecimento de mundo e de sua realidade. O autor João Brasil Monteiro é um bom exemplo dessa compreensão, seus livros têm por objetivo retratar aspectos da história da cidade de Marabá e traz um vocabulário que remete a esses diferentes aspectos, refletindo em suas escolhas lexicais tanto seu estilo de escrita quanto aspectos do falar regional.

\section{Estudos lexicais: cultura, identidade e memória}

A cultura reflete o modo de ser e de existir de um povo, constituindo-se das características locais, de seus saberes, costumes, valores e tradições, que formam a sua identidade, transmitindo-os e reafirmando-os mediante as memórias individuais e coletivas, sendo, portanto, indissociáveis da realidade de um povo. Assim, pode-se dizer que a cultura de um povo retrata seu presente e suas origens e possibilitando compreender suas possíveis manifestações e da identidade social qual o sujeito está inserido, em diferentes épocas. Como tal, a cultura não se pode ter como algo particular, e sim coletivo, produto de uma 
comunidade em que a dinamicidade é constante, pois as crenças, as leis, a moral não são estáveis, como algo pronto e acabado, de modo que as constantes transformações de comportamento na sociedade levam consequentemente a cultura a passar também por processos de transformações, bem como a identidade que caracteriza os indivíduos como membros de um grupo social, em cada época.

A identidade é um conjunto de marcas, constituídas simbolicamente, pelas relações sociais, que dá aos indivíduos o sentimento de pertença a um grupo ou de vários grupos sociais, pelo compartilhamento de elementos e traços comuns com os outros indivíduos, constituindo assim a cultura. Pode-se observar o que diz Eliassim e Coelho (2013, p. 2):

a identidade de um determinado grupo social se constitui a partir dos mecanismos simbólicos de representação do mundo e também das relações dos seres dentro deste mundo. Identificar elementos representativos de atividades profissionais é uma forma de verificar como um ser humano se relaciona com o mundo e com os demais seres, criando assim horizontes culturais dentro deste grupo específico.

Assim, identidade e cultura estão intimamente ligadas, assim como a memória, que, por sua vez, que armazena as experiências vividas por um indivíduo como ser social. Tratar de memória é tratar da cultura e identidade, pois ela é através dela que expressão cultural e identitária são vistas com mais nitidez, pois,

assim como são diversas as sociedades e culturas, o vocabulário veiculado pelos povos no decurso da história também possui diferentes facetas que o singularizam conforme o momento histórico da língua, a realidade geográfica, o perfil dos falantes [...]. (ISQUERDO, 2012, p. 115).

O amplo universo que todo povo possui é refletido no seu modo de falar, na sua linguagem, na sua língua. A língua torna-se um espelho das características dos seus falantes, como fenômeno social e dinâmico, visto que ela existe para a sociedade seja para interação, comunicação ou expressão do sentimento. Ela é herança e elemento essencial à constituição da identidade dos povos. Portanto,

língua e cultura são indissociáveis. A língua de um povo é dos mais fortes retratos culturais. Essa língua é formada por palavras que se organizam em frases para formar o discurso. Cada palavra selecionada nesse processo acusa as características sociais, econômicas, etárias, culturais, etc. de quem a profere. Sabemos de onde é uma pessoa no momento em que fala, pois cada povo tem sua língua e sua história. (ABBADE, 2012, p. 141).

Sendo assim, estudar o vocabulário de uma sociedade num dado momento implica reconhecer sua identidade cultural, já que a língua reflete todo um ambiente e as experiências vividas por um povo (SAPIR, 1969). Igualmente, como as sociedades e os membros dela se transformam, também a língua adquire certos traços decorrentes dessas transformações, o que mostra a importância dos seus estudos, em diferentes dimensões e abordagens teóricas, dentre 
os quais os estudos sobre léxico são os que mais demonstram a realidade e a experiência sociais, presentes ou passadas.

\subsection{Estudos lexicológicos}

De acordo com Abadde (2012), a lexicologia tem suas origens na Antiguidade Clássica, com Panini que elaborou sofisticados estudos sobre o sânscrito, língua sagrada da antiga Índia, no século IV a. C. Ainda no mundo clássico, os estudos lexicais ganharam espaço no ocidente com gregos, ali pelo século $\mathrm{V}$ a. C., depois com as contribuições dos estudiosos latinos tratando dos estudos gramaticais, mais tarde, durante a Idade Média, houve a preocupação de tratar propriamente da exatidão das palavras. A partir do Renascimento, ocorreu uma explosão com as confecções de dicionários de latim e de línguas nacionais. Antes do século XIX, apenas a lexicografia estava bem estabelecida, porém, com a chegada desse século, nasce a lexicologia por meio da comparação-histórica que abriu novos horizontes que fizeram estudar aspectos semânticos e socioculturais. Em 1952, aconteceu o VII Congresso Internacional de Linguística em Londres, que ocasionou uma base fenomenológica sobre esses estudos. Hoje, estudar o léxico vai muito além do que foi proposto no século XIX, pois ele se propõe a "[...] estudar a história e a cultura de quem utiliza essa língua" (ABBADE, 2012, p. 144), considerando que assim como os seres humanos se modificam, as línguas também se ajustam.

A lexicologia é um ramo do léxico que estuda propriamente as palavras tratando dos termos e suas definições, e, por meio dela, busca compreender as relações socioculturais da região e do povo falante da língua, tendo referências extralinguísticas nas mais diversas perspectivas. Consequentemente, a cultura é retratada a através desses estudos, como afirma Teixeira $(2015$, p. 65):

O léxico é o nível da língua que melhor representa o saber de um grupo sóciolinguístico-cultural, pois representa a via de acesso para ver e representar o mundo, deixando, portanto, transparecer os valores, as crenças, os hábitos e os costumes de um grupo social do qual o indivíduo faz parte.

Assim, o vocabulário das obras dos autores de uma região expressa realidade da a qual ele faz parte, então “[...] obter as impressões da expressividade das palavras da obra de um escritor é também obter as impressões do universo lexical da comunidade linguística à qual ele pertence" (FERREIRA, 2015, p. 33), pois, na obra fica demonstrada a realidade social por meio das palavras empregadas pelo autor, é caso o léxico regional expressado por um autor, como afirma Ferreira (2015, p. 33): 
o autor literário é não somente um criador de histórias e personagens, mas também um criador, ou recriador, da língua. E nessas (re)criações da língua é que resultam em toda uma carga semântica diferenciadora de como aquele usuário da língua se relaciona com seu objeto de trabalho. O uso dos vocábulos e as transformações neles impostas dão à escrita do poeta, do romancista e do contista a expressividade almejada, prova maior do estilo diferenciador dos escritores.

Isso significa que é impossível estudar a obra de um autor sem analisar o contexto sócio espacial onde ele está inserido, isso se aplica às escolhas lexicais nas suas obras, sendo possível traçar, por meio delas, as características culturais e identitárias de um povo.

Assim, pode-se concluir, conforme Nunes (2014, p. 38) que, o "léxico não é apenas o agrupamento de palavras de uma língua, mas um patrimônio em constante desenvolvimento e crescimento, pois as línguas são vivas assim como os seus falantes”. Em função disso, estudar o léxico de uma obra é uma forma de se conhecer o autor, mas, sobretudo, a realidade biossocial que o circunda.

\subsection{Campos léxico-semânticos}

O romeno Coseriu (1981), em sua obra Principios de Semántica Estructural, apresenta a teoria dos campos lexicais, segundo a qual o léxico de uma língua se organiza em vários campos nos quais se agregam vários termos com significados semelhantes. Abbade (2009, p. 38)

[...] o campo léxico representa uma estrutura, um todo articulado, onde há uma relação de coordenação e hierarquia articuladas entre as palavras que são organizadas à maneira de um mosaico: o campo léxico. Nesse sentido, as palavras que ocupam determinado campo estão individualmente determinando seus significados pelo número e pela situação, as palavras estão organizadas em um campo com mútua dependência, ou seja, elas adquirem uma determinação conceitual a partir da estrutura do todo.

Os campos léxicos refratam a experiência social nos mais diferentes e em todos os aspectos da existência humana, seja qual for o grupo social. Por eles, pode-se compreender como uma dada sociedade se organiza e como compreende o mundo em que vive. Entretanto, delimitar quais termos fazem parte de um determinado campo lexical não é uma tarefa simples, é necessário, antes de qualquer tudo, conhecimento vocabular e um olhar aguçado para identificar e classificar um termo na constituição de um campo. Com base em Pinto (1977), Nunes (2014, p. 37) sustenta a seguinte ideia:

Delimitar um campo lexical é ter consciência de seus limites em uma dada realidade linguística, pois as lexias se reunirão não apenas pelo fato de possuírem significados parecidos, mas por possuírem também um mesmo traço semântico, uma mesma característica fonética, fonológica ou, ainda, morfológica, e que os une pelo compartilhamento de uma mesma situação, finalidade, texto, regularidade, paradigma ou sentido de linguagem. 
Portanto, a organização de um vocabulário por meio de campos semânticos permite compreender como os elementos que compõem o léxico de uma língua se encontram interrelacionados por aspectos internos, linguísticos, e por aspectos semânticos que remetem à realidade externa da língua; além disso, permite compreender a própria organização da realidade social em suas diferentes manifestações. Assim, trata-se de uma abordagem teórica de grande utilidade para a compreensão da língua e da realidade por ela retratada, em conformidade com a visão de mundo de um grupo social.

\section{O vocabulário do autor João Brasil: breve histórico da cidade de Marabá}

A cidade retratada na obra de João Brasil Monteiro, Marabá, situa-se na mesorregião Sudeste do estado do Pará, distante a $500 \mathrm{~km}$ da capital, Belém. Sua população atual é de habitantes $275.086^{3}$, distribuída numa área total de $11.273 \mathrm{~km}^{2}$. A história do município é marcada pelos vários ciclos econômicos e os consequentes fluxos migratórios, responsáveis pela diversidade da população atual. A primeira grande leva de migrantes deve-se à chegada de maranhenses, goianos e piauienses à região, devido à descoberta de matas de caucho no início do século XX. Esta descoberta tornou a região uma das maiores produtoras de látex do mundo e possibilitou a criação de um pequeno núcleo do qual se originou a cidade, sendo o município oficialmente instalado em 05 de abril de 1913. Com o declínio do látex, seguiu-se o período de extração da castanha-do-pará, levando Marabá a tornar-se um importante centro comercial. Em 1937, teve início um novo ciclo de exploração determinado pela exploração de diamantes, período também marcado por grande prosperidade econômica.

A construção da rodovia Belém-Brasília, em 1960, e de outras estradas, elevou consideravelmente o contingente populacional para algo em torno de 20.089. A abertura da Transamazônica ampliou ainda mais o acesso permitindo a chegada de mais indivíduos e empresas atraídos pela política governamental de desenvolvimento da Amazônia. Em 30 de outubro de 1970, o município foi declarado Área de Segurança Nacional, como consequência do conflito armado conhecido como Guerrilha do Araguaia. Nos anos seguintes, iniciativas de grande porte, tais como a construção da Hidrelétrica de Tucuruí e a criação do Programa Grande Carajás, expandiram ainda mais as potencialidades da região elevando a população para 59.915 habitantes. Em 1980, a descoberta do garimpo de Serra Pelada, a $100 \mathrm{~km}$ da cidade, atraiu uma massa humana em tempo recorde, de forma que, em 1988, a população já ultrapassava o número de 90 mil habitantes (cf. MATTOS, 1996). Os migrantes instalados em

\footnotetext{
${ }^{3}$ IBGE - 2018.
} 
toda a região passaram a exercer diversas atividades, a maioria ligada à exploração da terra, como agricultores, pecuaristas, madeireiros e carvoeiros. Estas ocupações envolveram uma problemática altamente complexa que resultou na devastação da floresta, no confronto entre grandes e pequenos proprietários e entre estes e as populações indígenas (cf. Reynal, s.d.). Atualmente, a cidade conta serviços essenciais básicos e uma ampla via de acesso através de malha viária, além de transporte ferroviário e aéreo. A principal atividade produtiva é a pecuária, além da mineração e da produção extrativa. O comércio local é bastante diversificado. Do ponto de vista econômico, pode-se dizer que a configuração atual diferencia-se bastante daquela promovida pela colonização, inicialmente orientada para o comércio de gado e para o garimpo. Como consequência dos sucessivos ciclos econômicos e do intenso fluxo migratório, pode-se dizer que Marabá, bem como toda a região Sudeste do estado, constitui-se num grande mosaico de identidades culturais.

\subsection{Breve biografia de João Brasil}

O autor cuja obra pesquisamos, João Brasil Monteiro, nasceu em 25 de maio de 1926, em Altamira (PA), mas chegou com sua família ainda criança a Marabá (PA), em 1932. Nessa cidade, cresceu, estudou até o $3^{\circ}$ ano colegial e ainda adolescente começou a trabalhar como ajudante em oficinas de barcos que trafegavam nos rios da região fazendo o transporte de produtos como a castanha do Pará. Já mais velho, assumiu o trabalho de condutor de barcos, por décadas, cuja experiência retrata em suas obras. Foi também político, sendo eleito, por 3 vezes, como prefeito e vereador nas cidades de Itupiranga, Nova Ipixuna e Jacundá, próximas a cidade de Marabá.

Sua obra literária se inicia por volta dos anos 1990 (algumas obras não têm data), a última publicada em 2011, totalizando 11 obras - Viagem ao Tocantins, Araguaia e Itacaiúnas 1997; Do Capotão ao Poliuretana - 1998 ; O Castanheiro - 2001;. Marabá, Caminhos das Águas 2002; Pegadas de um Paraense - 2003; O Garimpeiro - 2004 (2 ${ }^{\mathrm{a}}$ ed.); Mair-Aba, Coração de Mãe 2006; A morte é, ou não a última palavra? - 2011; Biografia do Mestre Barata (S/D); Fique por dentro (S/D); História de Itupiranga e de Sua Gente (S/D) -. Bastante ativo no período, ele atuou ativamente para a criação da Academia de Letras do Sul e Sudeste Paraense ${ }^{4}$, sendo seu presidente de honra. Suas publicações tem caráter memorialístico, pois buscam retratar a

\footnotetext{
${ }^{4}$ Em 2009, o escritor foi reconhecido nacionalmente como Mestre da Cultura Popular Brasileira, no projeto Ação Griô, desenvolvido pelo projeto Galpão de Artes de Marabá (GAM).
} 
história da cidade em seu processo de formação, desde sua fundação em 1913 até a década de 1980.

\subsection{A pesquisa}

Essa pesquisa se encontra em andamento, tendo sido iniciada em 2017, com o apoio do CNPq. O trabalho tem como objetivo geral elaborar um vocabulário do autor regional João Brasil Monteiro, considerando que sua obra traz em sua obra unidades léxicas que remetem tanto ao estilo do autor como ao falar regional, ao mesmo tempo em que retrata o universo físico, social, histórico e cultural da cidade de Marabá. A identificação dessas unidades leva em consideração diferentes critérios, dentre eles o de remeter a aspectos próprios da realidade retratada nas obras e outros que consideramos pertinentes à pesquisa em questão, dentre os quais os descritos por HAENSCH (apud BRASIL, 2011). Além disso, são feitas consultas a dicionários especializados de língua e glossários regionais para fins de comparação, conforme os objetivos apresentados, e ampla pesquisa bibliográfica da literatura especializada, o mesmo sendo feito para a elaboração das definições, para as quais também se leva em conta o contexto onde estão inseridas. Assim, nota-se que a apresentação do vocabulário é "[...] semasiológica, partindo da palavra para o conceito [...]" (PONTES; MONTEIRO, 2014, p. 245).

A constituição do corpus se faz a partir de três (3) obras, que, ao nosso ver, traz elementos importantes da história, da natureza e da cultura local: Viagem ao Tocantins, Araguaia e Itacaiúnas (1997), O Castanheiro (2001) e Mair-Abá, Coração de Mãe (2006). A primeira trata da importância da atividade marítima da região; a segunda, da atividade econômica da castanha do Pará durante a primeira metade do século XX e a terceira, do processo de formação do município de Marabá e a chegada dos migrantes.

Tendo como base, a teoria dos campos semânticos elaborada por Coseriu (1981), foram identificados 12 campos semânticos: acidentes geográficos; alimentação e cozinha; atividades profissionais; convívio e comportamento social; fauna e flora; Fenômenos naturais; instrumentos de navegação; localização geográfica; objetos e materiais; saúde; vida urbana; povos e população.

Até o momento foram identificados e definidos mais de 300 vocábulos e fraseologias. Para a produção do vocabulário, utilizamos a ferramenta computacional Lexique Pro que faz que software possibilita criar uma ficha terminológica sem o risco de se deixar perder dados, 
haja vista que ele "[...] foi desenvolvido especialmente para elaboração de glossários e dicionários eletrônicos" (LIMA; MARTINS, 2014, p.259), além de ter a possibilidade de exportação de documento em formato em Word.

Os termos são apresentados em ordem alfabética e classificados por campos semânticos, com as respectivas informações na sua microestrutura, seguindo modelos de Nunes (2014):

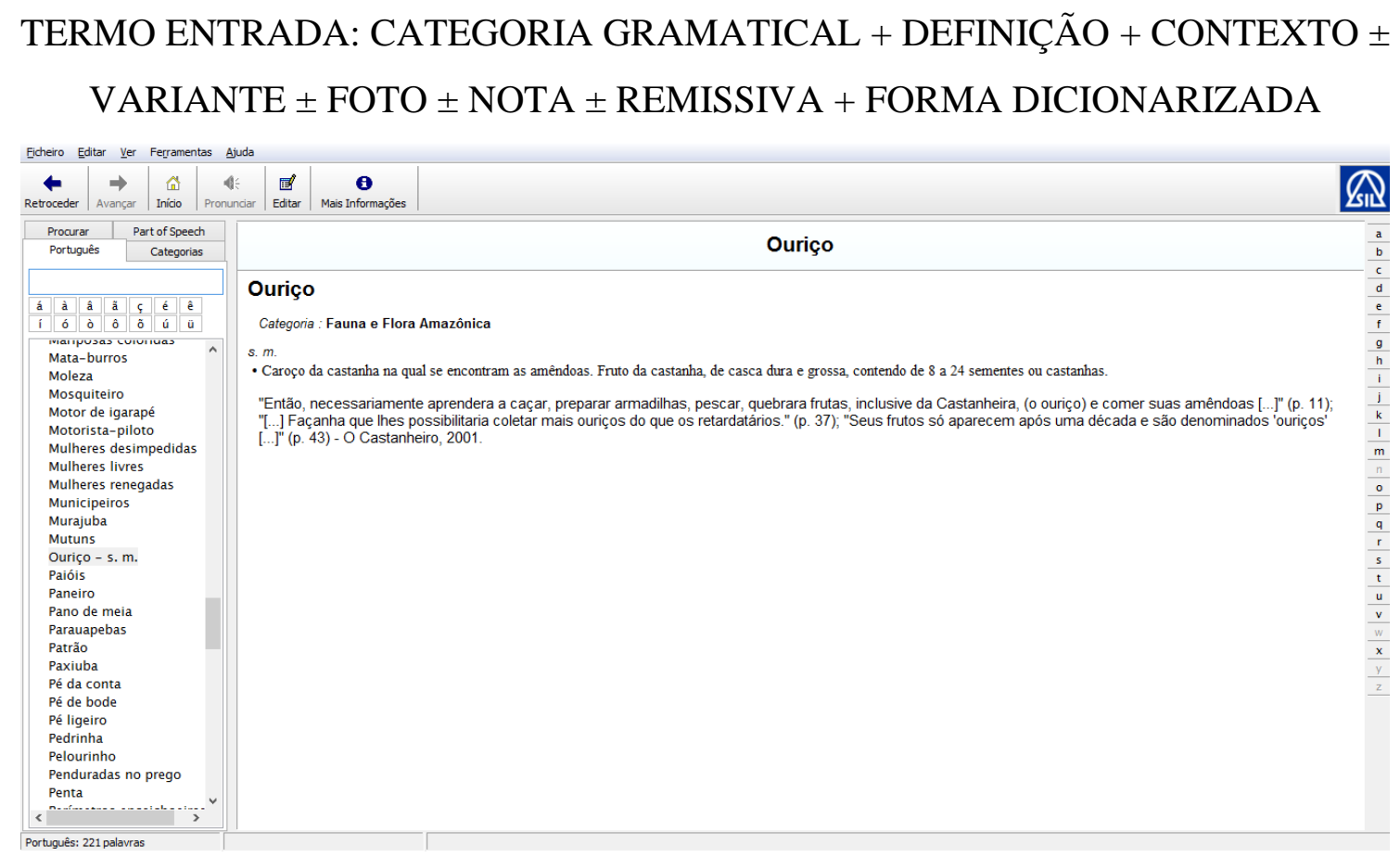

Figura 1 - Item lexical no programa Lexique Pro

Fonte: próprios autores

\section{Pequena amostra do vocabulário de João Brasil}

Como dito anteriormente, essa é uma pesquisa em andamento, mas já foram identificados 12 campos semânticos, nos quais se distribuem mais de 300 itens lexicais e fraseologias em três obras: O Castanheiro (2001) e Mair-Abá, Coração de Mãe (2006), estando a última, Viagem ao Tocantins, Araguaia e Itacaiúnas (1997), em análise. Como forma de ilustração, apresentamos uma pequena amostra do material já coletado. Nessa amostra, a sigla OC indica que o contexto foi retirado da obra $O$ Castanheiro.

Armadores s.m. Proprietários de barcos que transportavam a castanha. "Como fortes produtores foram mais além, expandiram a navegação tornando-se os principais armadores e empregadores do sul e sudeste paraense." (OC, p. 55) 
Bago s.m. O mesmo que castanha. "E em novembro, retornavam ao caminho dos castanhais devolutos do Pará a fim de extraírem o 'bago', a castanha.” (OC, p. 39) Ver : Castanha.

Barracão s.m. 1. Nome da primeira casa comercial de Marabá, inaugurada por Francisco Coelho, no Pontal. 2. Construção de madeira feita para servir como ponto de apoio aos castanheiros nos castanhais, onde se fazia negociações e se entregava e depositava a castanha coletada. 3. Casas em Marabá, às margens do Tocantins, onde se depositava a castanha para posterior exportação. "[...] onde havia rastros de construções diferenciadas e sobre os escombros, construíram um barracão, com estrutura de madeira, cercado de barro amassado e coberto com folhas de palmeira, portas e janelas [...]” (OC, p. 22)

Batelões s.m. Transporte fluvial impulsionado por remos e varas, bastante utilizado para transporte de carga pesada, na época da exploração do caucho. "E pela primeira vez, assim que ajuntaram um volume considerável, carregaram com castanhas dois batelões que, acionada a remos desceram o Rio Tocantins [...]” (OC, p. 35)

Cabelo Seco s.m. Bairro histórico, antigo Pontal, onde instalou se Francisco Coelho, que deu origem à cidade de Marabá. "Esse, depois de adquir uma casinha no bairro Cabelo Seco, nela, instalou seu laboratório de drogas francesas.” (OC, p. 53)

Castanha s.f. O mesmo que Castanha do Pará. Fruto da castanheira, extraído do ouriço, comercializado em larga escala durante o período econômico denominado ciclo da castanha, iniciado na década de 1920, sendo exportada em larga para Europa e EUA durante a segunda Guerra Mundial. Até 1980 era atividade extrativista principal na região. "[...] li-os com cuidado e atenção, e assim revivi, recordei e mesmo conheci, parte da história da castanha do Amazonas e países da América do Sul [...]" (OC, p.10).

Castanhais s.m. Áreas de terra onde era feita a exploração de castanha do Pará. Inicialmente, a exploração era de acesso livre. A atividade passou a ser restrita após a instalação do município, em 1923, em terras do município, as terras devolutas, atraindo migrantes do Maranhão, Goiás e Piauí. Nessa fase, eram concedidas matrículas para a extração, que iniciava no dia 02 de dezembro. Posteriormente, em 1947, por decisão política, as áreas devolutas do estado, foram cedidas por aforamento perpétuo ou por compra a membros da elite local. Essas áreas chegavam a 48.795 hectares. O autor registra os seguintes Castanhais: Macaxeira; São José; Pau Preto; Abóbora; Sampaio, Axixá. "Os proprietários de castanhais que realmente precisavam do braço humano, os encontrava através de seu encarregado, os encontravam exatamente em casa de refeições e cabarés, gastando o resto do minguado trocado que ainda possuíam, ali mesmo os contratava." (OC, p. 45) 
Castanheiro s.m. 1. Trabalhador na extração da castanha e na quebra do ouriço. Comumente, como o autor mesmo explica, era um indivíduo sem profissão definida que buscava trabalho como coletor de castanha e na quebra do ouriço na época da safra, ou seja, no início do inverno amazônico. De diferentes origens geográficas, segundo o autor, eram, sobretudo, amazonenses, paraenses, maranhenses, goianos e piauienses. Esses indivíduos penetravam nas matas, às quais chegavam por meio de embarcações, que pertenciam aos donos dos castanhais. O trabalho era feito pelo sistema de aviamento ou aviação. 2. O castanheiro conseguia coletar até seis caixas de castanhas por dia, quando a distância entre o barracão e o local de coleta era "razoável", no dizer do autor. "O Castanheiro é aquela pessoa, sem profissão definida e sem mercado de emprego, que deixa suas origens à procura de trabalho em outras regiões, empenhando-se na atividade de coleta de castanhas [...].”(OC, p.43)

Embiricicas s.f. Pranchas feitas com a borracha do caucho, depois de prensadas, serviam como transporte pelos rios e caucheiros, no retorno das matas. "[...] passaram a trabalhar ininterruptamente extraindo caucho, o suficiente, para preparar embiricicas e o carregamento dos seus barcos." (OC, p. 24)

Farinha de puba s.f. Tipo de farinha obtida da mandioca fermentada, muita consumida na região e base da alimentação do castanheiro, dado seu baixo custo e por ser não perecível. "I...] misturado ao leite de castanhas com farinha de puba, da jabota gorda também o leite e do fígado dela queimado na brasa e outras iguarias, que só nas matas paraenses são encontradas."(OC, p.63)

Gongo s.m. Calção masculino, utilizado pelos castanheiros. "Ao atracarem na ribanceira do Pontal, pulavam ainda de gongos molhados, para conhecer o barracão de farras [...]" (OC, p. 25)

Limpeza s.f. Retirada de mato de picadas e estradas para passagem de tropas de burros e castanheiros; o mesmo se fazia nas calhas de grotões e igarapés. "[...] roçados para o plantio de ilho e arroz, limpeza em picadas, estradas pera tangidas de burros, calha de grotões e igarapés, mata-burros e pequenos pontilhões.” (OC, p. 55)

Marabá s.m. 1. Nome dado à casa comercial, também denominada de Barracão, por Francisco Casemiro de Sousa, em alusão a uma antiga casa comercial de seu pai em Grajaú (MA), que deu nome à cidade. 2. Município do estado do Pará, localizado na região sudeste, situado a cerca de 500 quilômetros da capital, Belém. Foi fundado em 05 de abril de 1913. 3. Primeiro bairro da cidade de Marabá, cuja primeira denominação foi Pontal, devido localizar-se na faixa de terra que se forma no encontro dos rios Tocantins e Itacaiúnas. Atualmente, também denominada Marabá Velha, Velha Marabá ou Marabá Pioneira. "Foi nessa oportunidade de que Francisco Casimiro de Sousa, sócio de Chico Coelho da Silva deu o nome de Marabá [...]"(OC, p. 23)

Mariposas coloridas s.f. Mulheres profissionais do sexo que trabalhavam no Barracão, no Pontal. "[...] para conhecer o barracão de farras, onde as mariposas coloridas os recebiam com o brinde da casa, cachaça tiquira." (OC, p.25) 
Ouriço s.m. Caroço da castanha, de forma esférica, com cerca de 10 a 14 centímetros de diâmetro. Com casca dura e grossa, contém de 8 a 24 sementes, comumente denominadas castanhas. Sua queda se dá no período de inverno amazônico, que vai dezembro a março. Para se obter o fruto, é preciso quebrar o ouriço, atividade do castanheiro. "Então, necessariamente aprenderam a caçar, preparar armadilhas, pescar, quebrar frutas, inclusive castanheiras, (o ourico) $e$ comer suas amêndoas $[\ldots .] ".(O C, p .11)$

Picadas s.f. Caminhos feitos a facão nas matas para travessia de castanheiros, animais de carga e boiada. "I...] tocaram sua boiada de aproximadamente 40 reses, através das picadas abertas para animais de cargas e boiadas [...]" (OC, p. 19)

Remos voga s.m. Remos utilizados para propulsionar balsa pelo rio, segundo o autor. “[...] desceram a ribanceira e embarcaram juntos a boiada, numa barcaça de madeira propulsionada a remos 'voga' até a margem oposta daquele rio.” (OC, p. 19)

Rio Taká-y-una s.m. Rio que passa por Marabá e nome de um grupo indígena que habitava suas margens, segundo o autor. Atualmente denominado rio Itacaiúnas. "O Padre Manuel Nunes em 1669 subiu o rio Tucanotin, hoje Tocantins, e atingiu o Rio dos Taká-yuna, onde habitavam os índios do mesmo nome."( OC, p.14). “Os índios daquela região chamam a castanha de 'TAKA', porém, como suas amêndoas ter cor escura a chamam 'TAKA' - UNA'. Como na língua Geral o ' $Y$ ' significa água ou rio, daí o nome da tribo e do Rio, TAKÁ - Y -UNA .” (OC, p.16).

Ubá s.m. Tipo de embarcação usada no período de instalação do Pontal. "[...] embarcaçães denominadas, ubás, igarités, balsas, embiricicas de caucho, canoas, batelões e botes [...]" (OC, p. 28)

\section{Conclusões}

Neste trabalho, estudamos o vocabulário de um autor marabaense, cuja obra pode ser considerada de caráter memorialista. Assim, por meio desse estudo, pudemos ter acesso tanto ao conhecimento a memória cultural e social de uma sociedade, em um certo período de sua história, quanto do vocabulário de seu autor.

Desse modo, consideramos que esses estudos contribuem tanto para o registro e o conhecimento do dialeto regional, quanto para os campos de estudos nos quais se fundamenta essa pesquisa, considerando que as obras literárias podem refletir o vocabulário da comunidade à qual o escritor pertence, como falante, sendo assim, também contribuímos para o conhecimento do léxico regional e consequentemente para a valorização da literatura da região.

\section{Referências}

ABBADE, Celina Márcia de Souza. Lexicologia social: a lexemática e a teoria dos campos lexicais. In: ISQUERDO, Aparecida Negri; SEABRA, Maria Cândida Trindade Costa de 
(Org.). As ciências do léxico: lexicologia, lexicografia, terminologia. 6 ed. Campo Grande MS: UFMS, 2012. p. 141-161.

ABBADE, Celina Márcia de Souza. Um estudo do léxico do primeiro manuscrito da culinária portuguesa medieval: o livro de cozinha da Infanta D. Maria. Salvador: Quarteto, 2009.

BRASIL, Marta Maria da Silva. O vocabulário de Godofredo Filho. 2011. 208 f. Tese de Doutorado (Pós-Graduação em Letras e Linguística) - Instituto de Letras, Universidade Federal da Bahia, Salvador. 2011.

COSERIU, Eugenio. Principios de Semántica Estructural. Madrid: Gredos, 1981. Tradução de M. M. Hernandez.

ELIASSIM, Cristiano Curtis; COELHO, Braz José. Identidade, cultura e linguagem - léxico relativo às atividades profissionais em Tropas e Boiadas, de Hugo de Carvalho Ramos. In: SILEL, 1., 2013, Uberlândia. Anais... Uberlândia: EDUFU, 2013.

FERREIRA, Raphael Bessa. Léxico amazônida e poética amazônica em Altar Em Chamas, de Paes Loureiro. In: FARGETTI, Cristina Martins; MURAKAWA, Clotilde de Almeida Azevedo; NADIN, Odair Luiz (Org.). Léxico e cultura. Araraquara - SP: Letraria, 2015. p. 33-38.

ISQUERDO, Aparecida Negri. Léxico regional e léxico toponímico: interfaces linguísticas, históricas e culturais. In: ISQUERDO, Aparecida Negri; SEABRA, Maria Cândida Trindade Costa de (Org.). As ciências do léxico: lexicologia, lexicografia, terminologia. 6 ed. Campo Grande - MS: UFMS, 2012. p. 115-139.

JADÃO, Paulo Bosco Rodrigues. Marabá: a história de uma parte da Amazônia. Marabá: Prefeitura de Marabá, 1984.

LIMA, Alcides Fernandes de; MARTINS, Arlon F. Carvalho. Utilização do programa Lexique Pro na elaboração de glossários e dicionários terminológicos. In: RAZKY, Abdelhak et al (Org.). Estudos sociodialetais do português brasileiro. Campinas - SP: Pontes Editores, 2014. p. 257-277.

MATTOS, Maria Virgínia Bastos de. História de Marabá. Marabá: Grafil, 1996.

MONTEIRO, João Brasil. Mair-abá, coração de mãe. Marabá, 2006.

MONTEIRO, João Brasil. O castanheiro. Marabá, 2001.

MONTEIRO, João Brasil. Viagem ao Tocantins, Araguaia e Itacaiúnas. Marabá, 1997.

NUNES, Ticiane Rodrigues. Glossário de termos do campo lexical violência nos autos de querela do século XIX. 2014. Dissertação (Programa de Pós-graduação em Linguística Aplicada) - Centro de Humanidades, Universidade Estadual do Ceará, Fortaleza.

PINTO, Milton José. Análise semântica de línguas naturais: caminhos e obstáculos. Rio de Janeiro: Forense-Universitária, 1977. 
PONTES, Antônio Luciano; MONTEIRO, Jamyle dos Santos. Interface entre geolinguística e lexicografia regional: o caso do atlas linguístico. In: RAZKY, Abdelhak et al (Org.). Estudos sociodialetais do português brasileiro. Campinas - SP: Pontes Editores, 2014. p. 243-255.

PREFEITURA MUNICIPAL DE MARABÁ. Viagem ao Tocantins. Marabá, 1983.

SAPIR, Edward. Língua e ambiente. In: SAPIR, Edward. A linguística como ciência. Rio de Janeiro: Livraria Acadêmica, 1969. p. 43-62.

SILVA, Idelma Santiago da. Fronteira Cultural: a alteridade maranhense no sudeste do Pará (1970-2008). 2010. Tese (Programa de Pós-Graduação em História) - Universidade Federal de Goiás, Goiânia, 2010.

TEIXEIRA, Maria da Conceição Reis. Representação do sertão baiano em Seara Vermelha, de Jorge Amado: o campo lexical dos trabalhadores. In: FARGETTI, Cristina Martins; MURAKAWA, Clotilde de Almeida Azevedo; NADIN, Odair Luiz (Org.). Léxico e cultura. Araraquara - SP: Letraria, 2015. p. 65-71.

VALE. Marabá, ontem e hoje. Marabá, 2013. 